Investigations

\title{
Morphogenetic and Biochemical Study on University Common Bean Collection
}

\author{
Beibitgul Zhumabaeva, Erika Dzhangalina, Zaure Aytasheva, \\ Lina Lebedeva, Zarina Inelova and Zhanar Chunetova \\ Al-Farabi Kazakh National University, 71 al-Farabi Ave., \\ Bldg. 6, Almaty 050040, Republic of Kazakhstan
}

\section{Article history}

Received: 04-08-2017

Revised: 31-10-2017

Accepted: 24-11-2017

Corresponding Author: Beibitgul Zhumabaeva Al-Farabi Kazakh National University, 71 al-Farabi Ave., Bldg. 6, Almaty 050040, Republic of Kazakhstan Email: Beibytgul.Zhumabaeva@kaznu.kz

\begin{abstract}
This research has been conducted to reveal the outcomes of rotation of crops in mountain and steppe districts near Almaty. The main morphogenetic characteristics have been investigated for the collection of representatives of common bean, Phaseolus vulgaris L. by using samples from various countries such as Kazakhstan, USA, China, Czech Republic, Poland, Turkey and Russia under different climate and soil conditions. A series of useful genetic stocks for the main economically valuable traits were detected. Several introduced varieties of common bean have showed high seed germination, maturation and significant resistance to water deficit, whereas some Kazakhstani varieties have been exceeded certain foreign specimens and varieties by weight of seeds and other parameters. It has been proven that "Luna" belonging to Czech collection would ripe the first (80 days from planting to complete technical maturity). Other varieties could approach the same conditions 10-12 days later. Using local specimen "Aktatti", the effect of new bio organic mineral fertilizer produced by the Faculty of Chemistry has been demonstrated on morphogenetic traits of common beans. Basic catalogue of common bean resources including approximately 40 parental varieties and specimens of Phaseolus vulgaris $\mathrm{L}$. and their relatives originally from different geographic regions has been compiled. It is planned to complete it by six bushy and runner representatives of French collection. The data have been completed by quantitative and qualitative amino acid evaluations. Kazakhstani and foreign cultivars and specimens respectively have been groupped by the data on amino acid composition of seeds which was analized by the method of liquid chromatography. Essential amino acids have approached approximately of total amino acids pool in Kazakhstani specimens. If tyrosinylation index (Phe/Tyr ratio) for local specimens achieved $0.90-0.95$, similar index for external varieties was equal to $0.88-0.89$. This difference may accentuate the role and the quality of membrane proteins in local lines strengthening a composite stability (resilience, temperature and metabolic) in comparison with international common bean specimens under present study.
\end{abstract}

Keywords: Common Bean, Variety, Catalogue of Stock Resources, Amino Acid Composition

\section{Introduction}

The process of cultivation of Phaseolus vulgaris L. populations or hybrids may be predicted from natural hybridization and natural selection of these forms which are adapted to changing climate conditions within the habitats. As a consequence crops would spread from these areas to new territories. Transformation of wild species keeps on extensively because of human activities, as the most valuable plants for feeding and life have been selected for the following cultivation (Bodnar and Lavrinenko, 1977).

During the process of evolution only plants with unique traits such as early germination and maturation, bush, type of growth, large or medium leaves and flowers, non-dehiscence and the absence of pergament layer in pods have been selected (Zhukovsky, 1971). In comparison to other legumes, Phaseolus vulgaris L is referred as more capricious to soil conditions due to its 
preference of light, fine grained clay-containing plastic

Cold and humid fine grained soils containing clay are not suitable to breed common bean. In addition, under high level of acidification, soil compaction and turf formation can also contribute to the negative effect of crops degradation (Popov and Martynov, 2001). Some heavy metals may significantly decrease production of common beans (Ratushnyak et al., 2012).

Due to acidic soils, the growth of nitrogen-fixing bacteria is suppressed. Usually it causes decreased amount of nitrogen in soil (Zerfus et al., 1997). To improve yields of common bean, it is necessary to minimize acidic soils or add some calcium to them. Interestingly, there are a lot of varieties of common beans cultivated in Kosovo, in combination with Zea mays or as a monoculture (Fetahu et al., 2013). It was determined that the stress had low impact on photosynthetic rates in common bean (Shekari et al., 2014). However, according to some authors, stress can influence on the process of photosynthesis in common beans (Shekari et al., 2014).

Under specific conditions in mountain and steppe zone in the region of Almaty, morphogenetic traits of 37 representatives of Kazakhstani, American, Chinese, Czech, Polish, Russian and Turkish collections have been assessed.

This experiment was conducted during two harvesting seasons in steppes and mountains. Both sites are located near the city of Almaty. 37 varieties and specimens were planted along with food and decorative pumpkins for the following purposes: I, to create and study Kazakhstani forms of common bean; ii, to create the collection to be explored by the university researchers and the students; iii, to develop the field and seed research capacities of Agrobiocenter at al-Farabi Kazakh National University; iv, to test composition of amino acids in different bean samples.

\section{Materials and Methods}

Current research was carried out during two seasons of field crop rotation in different regions such as mountain and steppe (plain) zones in the city of Almaty. 37 specimens of common bean and their relations were planted to accomplish the tasks described in the Introduction in details.

Part of stock specimens and varieties after preliminary propagation and introduction has been registered as the State Certificate on the subject of author rights No. 612 of 14 May, 2012 entitled "Distribution and exchange of bean specimens".

Varieties and specimens from the collection have been investigated according to protocols accepted by Awassa Agricultural Research Center and the Institute named after Vavilov (Korsakov, 1975; Asfaw et al., 2009). Seeds twice were put in special plots of $10 \times 2$ meters, through the use of the method of row sowing with the distance approximately 40-60 $\mathrm{cm}$ between rows. "Aktatti"specimen was a standard one in specific soils or coarse grained, fertilized sand soils. regional conditions of Almaty. Our computer software entitled "Manager of panting" was used to design the experiment and plant all common beans.

Seeds of 17 cultivars and specimens of Phaseolus vulgaris $\mathrm{L}$. were sown in the mountains. 20 cultivars and lines of common bean and its relatives (broad bean, Vicia faba L. and Turkish beans, Phaseolus coccineus L.) were planted in the steppe zone. Current work is concentrated on percentage of germination and length of pods and the content of amino acids in seeds. For this purpose the method of liquid chromatography was used. To increase germination we introduced $25-30 \mathrm{~g}$ of domestic bioorganic fertilized per plot 25-35 days after planting with moderate watering.

Six representatives of domestic and foreign collections have been were selected to clarify composition of amino acids by high-performance liquid chromatography. Quantitative and qualitative analysis of amino acids was performed on the basis of acidic hydrolysis of extraction from seed powder in the presence of $6 \mathrm{~N} \mathrm{HCl}$ at $105^{\circ} \mathrm{C}$ for $24 \mathrm{~h}$. The hydrolysate was then dried 3 times with rotory evaporator at $40^{\circ} \mathrm{C}$. The pellet obtained was resuspended with portions of sulfosalicylic acid and centrifuged to remove aggregated precipitates. Supernatant was exposed to liquid chromatography on the Dowex-50 coulmn at the elution rate equal to $150 \mathrm{l} / \mathrm{sec}$. After neutralization of the column with deionized water, amino acid factions were washed out with $6 \mathrm{~N} \mathrm{NH} 4 \mathrm{OH}$ (elution rate $300 \mathrm{l} / \mathrm{sec}$ ).

The eluate was dried with rotory evaporator under pressure of 1 atmosphere and $50-60^{\circ} \mathrm{C}$. Mixture of $\mathrm{SnCl} 2$, 2,2-dimethyl oxypropan and propanol saturated with $\mathrm{HCl}$ was added to dried preparation. Then it was incubated at high temperature (to $110^{\circ} \mathrm{C}$ ) for $20 \mathrm{~min}$ to be dried repeatedly. To conduct acetylation, dried pellet was treated with the mixture of acetic anhydride, triethanolamine and acetone $(1: 2: 5)$. The mixture was incubated at $60^{\circ} \mathrm{C}$ for $1.5-2 \mathrm{~min}$ and dried. The preparation was diluted with ethyl acetate saturated with $\mathrm{NaCl}$ solution. The upper phase containing ethyl acetate, after thorough agitation, was picked out. Gas chromatography of amino acids in the decanted phase was carried out by using "Carlo Erba 4200", Italy-USA. Amino acid elution was performed with a stainless-steel column $(40 \times 0.3 \mathrm{~cm})$ filled with polar mixture of $0.31 \%$ Carbowax 20m, 0.28\% Silar-5av and $0.06 \%$ Lexan on the Chromosorb WA-W-120-140m matrix. The standard regime of elution was maintained at the temperature of the flame ionisation detector $300^{\circ} \mathrm{C}$, evaporator temperature of $250^{\circ} \mathrm{C}$, initial column (furnace) temperature of $110^{\circ} \mathrm{C}$ and subsequent modes of column incubation: $6^{\circ}$ per min in the range of $110-185^{\circ} \mathrm{C}$ and $32^{\circ}$ per min in the range of 185 $250^{\circ}$. Maximum temperature of the column was supported until necessary fractions completely exited (Adams, 1974).

Statistic treatment of the data obtained was performed by the method of analysis of variance (Dospekhov, 1985; Bisgaard, 2008). 


\section{Results}

Common bean seeds have been planted in the mountain zone in two sites independently. The first site is located at the territory of the Institute of Botany and Phytointroduction of the Science Committee of the Ministry of Education and Science of the Republic of Kazakhstan; the second site lies in Almarasan Gorge along the River Bolshaya Almatinka (800-1200 $\mathrm{m}$ above the sea level). The steppe plots are presented at the territory of "Zhanga Talap" centre proprietary of al-Farabi Kazakh National University and Kazakh Institute of Soil and Crop Research (both nearly $600 \mathrm{~m}$ above the sea level).

9 varieties and specimens of Phaseolus vulgaris L., have been sown on plots of the Institute of Botany and Phytointroduction; 8 specimens have been planted in the Almarasan Gorge (mountain zone). 20 varieties and specimens of common bean and its relatives (broad bean, Vicia faba L. and Turkish beans, Phaseolus coccineus L.) have been planted in the "Zhanga Talap" Agrobiocenter (steppe zone). Studies of morphogenic traits in the process of germination, showed that local Kazakhstani varieties and specimens surpass samples from Czech collection (Fig. 1). Among all Czech samples of common bean, cv. "Zuzka" at the 30th day after planting demonstrated the highest level of germination. Two other varieties "Katka" and "Luna"showed lower germination (23.3 and 16.6\%, respectively). Also "Zuzka" has also been detected to interior other varieties and specimens by leaf size $(11.2 \times 8.0 \mathrm{~cm})$, whereas these parameters for "Katka" and "Luna" were $6.5 \times 4.5$ and $9.3 \times 6.4 \mathrm{~cm}$, respectively. At the same time "Zuzka" has approached the stage of flower formation earlier than other plants. The emergence value for "Zuzka" was much greater than percentages for other Czech common beans used for the experiment. This data has theoretical and evolutional significance because seed number and pods size, germination speed and lower length of stem in warm-seasonal legumes are construed as traits of domestication (Isemura et al., 2007). It has been revealed that common bean leaves possess oval or wide oval form under local conditions. In addition, some varieties and specimens revealed silver-polished stipules and different colour options for leaves, which is a genetic marker defining the variety. The colour is dependent on the vegetative stage of the plant, soil quality and amounts of fertilizers.

Introduction and adaptation of foreign varieties to Kazakhstani climate conditions are in progress. One of the factors influencing on the positive dynamics is genetic polymorphism and possibility to adapt foreign samples, especially the representatives from Czech collection. In the mountains not far from the city of Almaty (site in the Almarasan Gorge) it has been established that three varieties such as "Zuzka", "Katka" and "Luna" (Fig. 2) which were tried to be introduced in 2012 , demonstrated high productivity with the exception of "Jit ka", which did not germinate at all.

Seed material obtained from "Zuzka", "Katka" and "Luna" would be used for further breeding, at the territory of "Zhanga Talap" in the steppe zone. All Czech varieties have shown high resistance to pathogenic bean weevil (Acanthoscelides obtectus Sav.) at room temperature. "Luna" became the earliest riping variety with a maturation period of 80 days from the onset of ontogenesis. Other specimens have approached the stage of technical maturity 10-12 days later.

As we can see in the Fig. 2, the maximal size of mature pod was obtained only on the 92-th day after planting and belongs to "Zuzka" $(13.3+0.1 \mathrm{~cm})$. The pod size of "Katka" and "Luna" was approximately 12.0+0.2 $\mathrm{cm}$ and $10.8+0.1 \mathrm{~cm}$, respectively. The domestic specimen "Aktatti" had similar pod length in the range of $11.0+0.1 \mathrm{~cm}$, whereas other Kazakhstani representatives such as "Nazym" and "Talgat" had pod sizes of 12.4+0.1 and $9.0+0.2 \mathrm{~cm}$, respectively during the final stage of technical maturity.

Pod length values of "Zuzka" and "Talgat" have reliably excelled the same parameter of other cultivars and lines under investigation (Fig. 3).

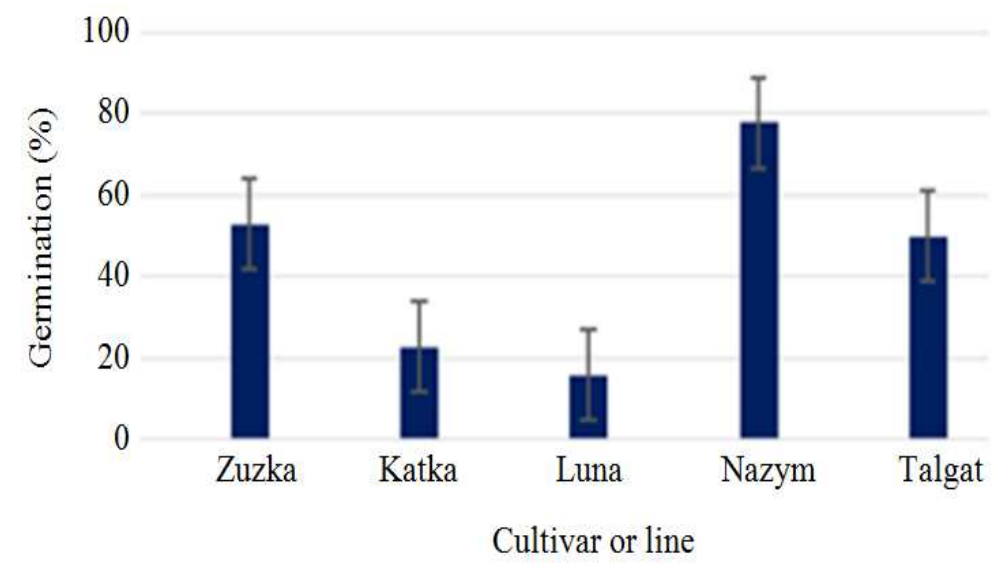

Fig. 1: Results of phenological observations: intermediate evaluation of germination of representatives of Kazakhstani and Czech collections of common bean (30-th day after sowing) 


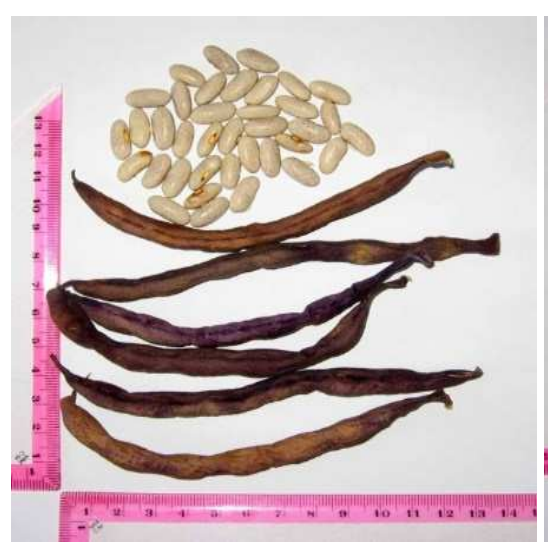

(a)

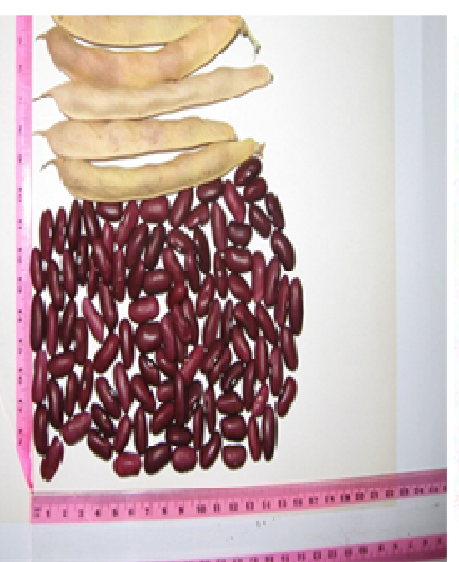

(d)

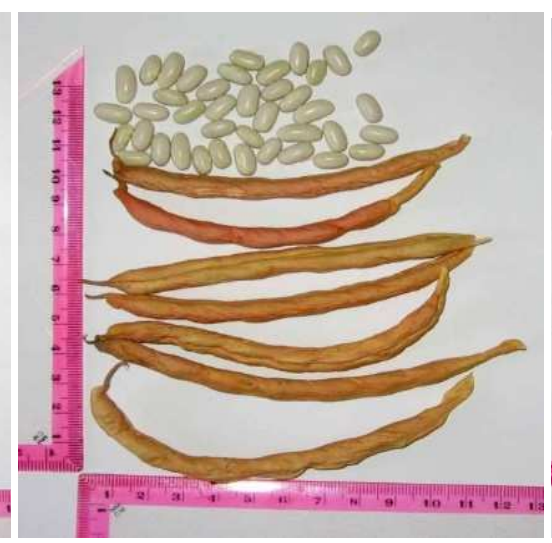

(b)

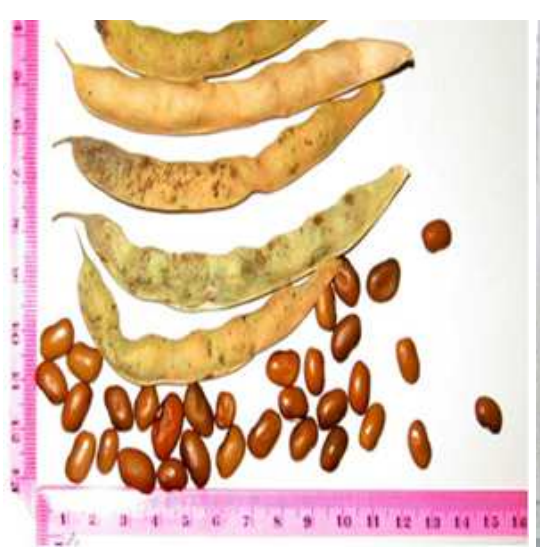

(e)

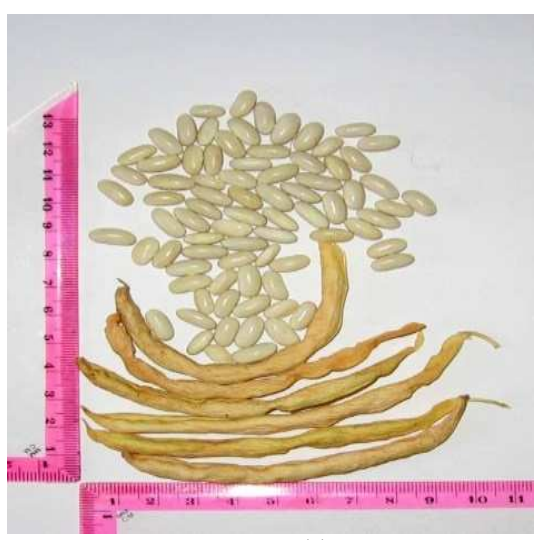

(c)

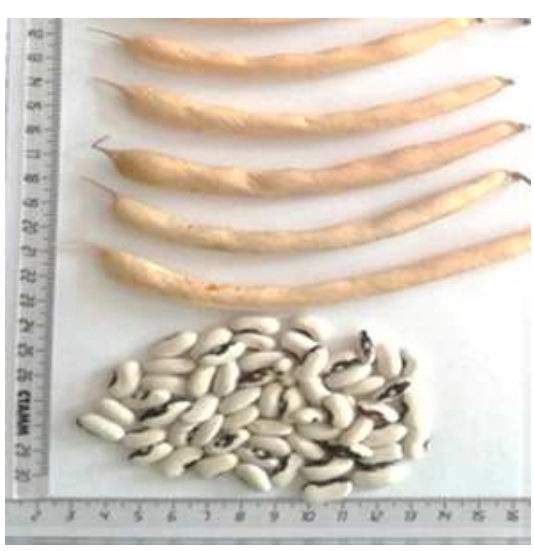

(f)

Fig. 2: Czech varieties and Kazakhstani secimens at the stage of technical maturity. (a) "Zuzka" (b) "Katka" (c) Luna (d) Nazym (e) Talgat (f) "Aktatti”

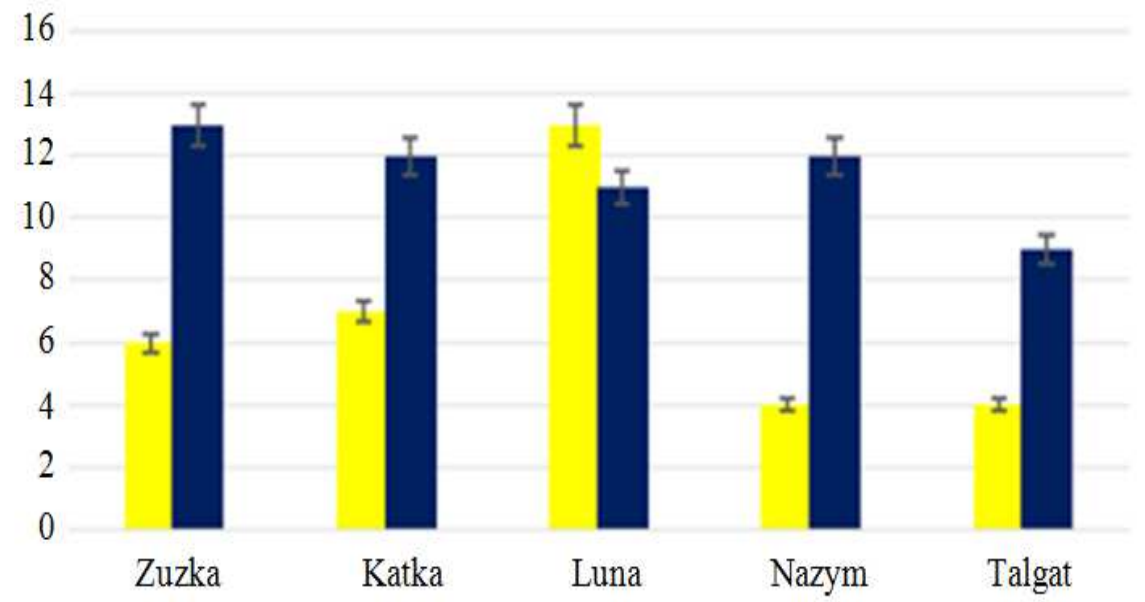

Cultivar or line

Number of seeds per pod

- Pod length $(\mathrm{cm})$

Fig. 3: Results of structural analysis of Kazakhstani and Czech varieties and specimens of common bean 


\section{Discussion}

As seen from present study, preferentially suitable cultivars for the steppe zone are "Red Goya", "Camelia", "Bijchanka" and "Ufimskaya". While implication domestic "Aktatti" line positive impact of modern mineralized bioorganic fertilizer has been revealed on morphogenetic traits including productivity of $P h$. vulgaris plants.

Current research is aimed at identification of superior lines obtained from a mountain location by phenotypic examination and comparing with exclusive Czech $P$. vulgaris cultivars. By the range of phenotypical characters (branch deviation, height, hypocotyl width, ripeness, lodging, disposition of upper pod, pod number per plant and productivity (Beattie et al., 2003), clusterization of available cultivars was carried out. In the Fig. 4 shown percentage of emergence, which was processed using computational cluster analysis, domestic form "Nazym" is noticed to be neighbouring to Czech cv. "Zuzka", whereas local line "Talgat" is being close to "Zuzka", too. However, "Talgat" is recorded to be quite distant from two other Czech accessions, namely cvs "Katka" and "Luna".

Judging by the studies fulfilled, "Nazym" specimen may be attributed to a unique line due to morphogenetic characters. Data of Fig. 4 include local and Czech varieties and specimens, as the latters were successively introduced into the mountain zone. Noteworthy, Wang et al. (2012) proposed similar approach demonstrating by their studies genetic resemblance of the European and the North African genotypes which were closely associated with their geographical origins and ecological state (Wang et al., 2012). Another adequate research towards the enrichment and analysis of national bean collection was fulfilled by Asfaw et al. (2009; Kumar et al., 2008). Chinese investigators (Zhang et al., 2008) attempted evaluating a collection of local samples for the genetic variability, genepool identity and relationships within and between the groups identified among the genotypes. The landraces in our reserch were clustered into two genepools. Earlier Polish researchers evaluated the genetic variability across commercial cultivars and domestic accessions of the dwarf and runner P. vulgaris types to reveal notable polymorphism among $P$. vulgaris and $P$. coccineus samples allowing to distinguish articulate sets of beans (Nowosielski et al., 2002). One of advantageous outcomes of present investigation is the amount of polymorphism in stocks and "open gate" towards inducing foreign varieties and the Czech collection in this particular case. Foothill experiments conducted in the Almarasan allowed to pick out three varieties such as "Zuzka", "Katka" and "Luna" possessing a highly desirable traits such as high yield and early maturity for further research. It was noticed that Czech genotypes have exhibited high responsiveness to Acanthoscelides obtectus Sav. (bean weevil) under normal conditions. One of Czech representatives ("Luna") was defined to be the earliest to reach maturity on 80-th day after planting. On the contrary, "Zuzka"and "Katka" were found to reach the same stage of maturity 1012 days later. Amino acid composition has indicated a range of essential amino acids in domestic bean lines comprising approximately $30 \%$ of total amino acid quantities. Due to most significance of lysine and thryptophan for plant growth, it has been demonstrated that the the Tyrosinylation Index (TI), or Phe/Tyr ration across local lines would be fixed around $0.90-0.95$, whereas TI for external cultivars would make up 0.88-0.89. This difference may accentuate the role and the quality of membrane proteins in local lines strengthening a composite stability (resilience, temperature and metabolic) in comparison with international common bean specimens under present study.

By the quantities of few amino acids (glutamate, aspartate, alanine and proline) local bean samples have been revealed to outstrip external cultivars more than 2 times. The unique features of local bean specimen "Nazym" are confirmed by computational estimation of the amount of essential amino acids as seen from Fig. 5.

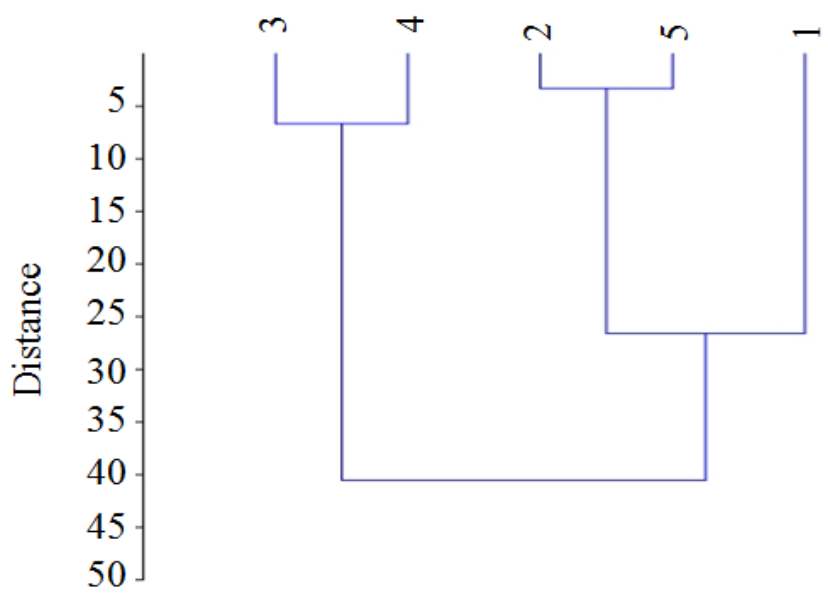

Fig. 4: Comparison of common bean cultivars and lines clustered by the germination rate exhibit differences of Kazakhstan and Czech collections of common bean (30-th day of sprouting) 1. Nazym, 2. Talgat, 3. Luna, 4. Katka and 5. Zuzka 


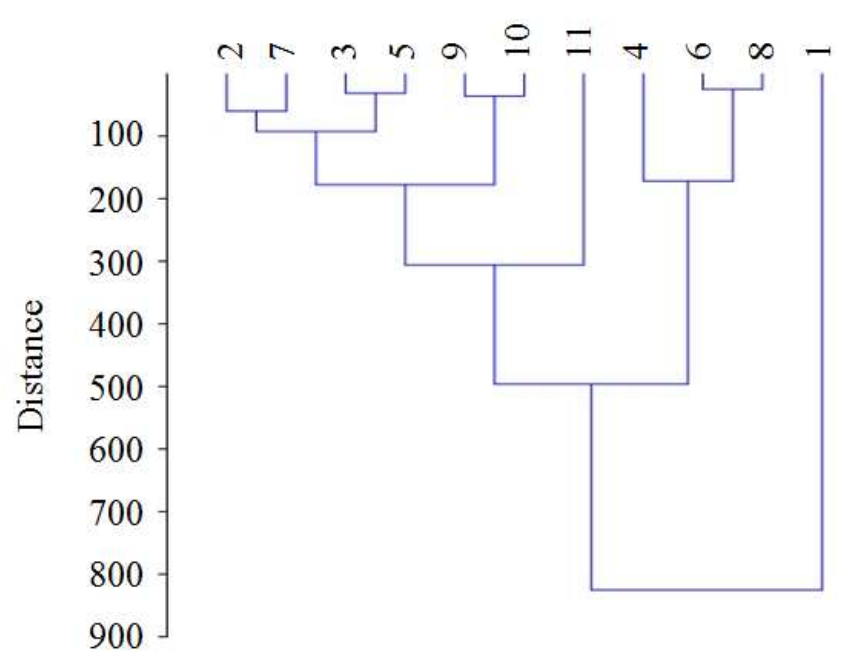

Fig. 5: Comparison of common bean varieties and specimens clustered by the differences in essential amino acid contents in reference of Kazakhstani and other international representatives 1. Nazym, 2. Talgat, 3. Luna, 4. Katka, 5. Zuzka, 6. Aktatti, 7. Bijchanka, 8. Camelia, 9. Dzhungarskaya, 10. Red Goya and 11. Ufimskaya

Table 1: List of research trends in common bean biology and biotechnology

\begin{tabular}{|c|c|c|}
\hline No & Research direction & Citation(s) \\
\hline 1 & Bean domestication history and studies on orphan (under-utilized) legumes & $\begin{array}{l}\text { Berrocal-Ibarra et al. (2002; } \\
\text { Cullis and Kunert, 2016; } \\
\text { Kwak et al., 2012; } \\
\text { Herrera et al., 2001; } \\
\text { Nanni et al., 2011; } \\
\text { Peña-Valdivia et al., 2010) }\end{array}$ \\
\hline 2 & $\begin{array}{l}\text { Bean plant physiology and biochemistry; food legume productivity } \\
\text { research; combined studies on dryland cereals and legumes }\end{array}$ & $\begin{array}{l}\text { Daryanto et al. }(2015 \\
\text { Hyman et al., 2016) }\end{array}$ \\
\hline 3 & Bean genetics and chromosome biology & Vasconcelos et al. (2015) \\
\hline 4 & Bean molecular biology; Bean RNA biology & $\begin{array}{l}\text { Büyük et al. }(2016 ; \\
\text { Hiz et al., 2014; } \\
\text { Kavas et al., 2016; } \\
\text { Sampath et al., 2012) }\end{array}$ \\
\hline 6 & Bean virology; genomoviral studies & Lamas et al. (2016) \\
\hline 7 & Bean symbiotic studies and bean pathology & $\begin{array}{l}\text { Ballhorn et al. (2016; } \\
\text { Marcenaro and Valkonen, 2016) }\end{array}$ \\
\hline 8 & Bean metabolic engineering and biofortification & Rivera et al. (2016) \\
\hline 9 & Bean dietology; bean nutrigenetics & Gómez et al. (2015) \\
\hline 10 & Bean volatiles research; bean signalomics & Zhang et al. (2012) \\
\hline
\end{tabular}

We investigated the influence of newly elaborated bio organic mineral fertilizer on morphogenetic traits of local "Aktatti" bean accession. The data have manifested that the yield under a new fertilizer can be increased by $19-25 \%$, regardless of climatic conditions.

Noteworthy, ongoing general progress in biology and biotechnology of legumes may be explained by tremendous diversification of the tree sub-branches in this research area. To specify this issue the authors have attempted to classify major trends in present legume studies as indicated in Table 1.

Analysis of morphogenetic traits across the available samples has led to compilation of the catalogue for main original varieties of $P$. vulgaris. The list includes approximately 40 parental specimens and their relatives of different initial origin. Out of the Czech bean varieties examined in the mountain zone, cv. "Luna" was detected to reach maturity the earliest (80 days of harvesting), whereas resting varieties have been recorded at technical maturity 10-12 days later. By germination rates verified by automated cluster test, the genotype "Nazym" was confirmed to be close by maturation period to cv. "Zuzka" and local speciment "Talgat". "Nazym" has appeared to be quite promising for commercial production in the South-East of Kazakhstan. "Nazym" has also been ascribed to be advanced by essential amino acids, taking over the reference genotypes under current study.

Besides Czech and local $P$. vulgaris genotypes forementioned, six French commercial accessions of bushy and runner common beans have indicated high or average 
productivity in our conditions. Since cv. "Argus" is specific by its hybridization ability, it is obvious that the studies on bean domestication, crossing and molecular biology are essential. Further development of domestic bean collection along with the application of another eight directions of biology and biotechnology of legumes requires efforts both from researchers and authorities involved.

Noteworthy, ongoing general progress in biology and biotechnology of legumes may be explained by tremendous diversification of the tree sub-branches in this research area. To specify this issue the authors have attempted to classify major trends in present legume studies as indicated in Table 1.

\section{Conclusion}

Analysis of morphogenetic traits across the available accessions has led to compilation of the catalogue for main original varieties of $P$. vulgaris. The list includes approximately 40 parental specimens and their relatives of different initial origin. Out of the Czech bean varieties examined in the mountain zone, cv. "Luna" was detected to reach maturity the earliest (2.5 months), whereas remaining genotypes have achieved maturation a fortnight later. According to cluster testing by germination rates, local specimen "Nazym" was confirmed to be close by maturation period to cv. "Zuzka" and local specimen "Talgat". "Nazym" has appeared to be quite promising to be grown commercially in South-East regions of Kazakhstan. Local specimen "Nazym" is also referred to be advanced according to the essential amino acids content, taking over the reference cultivars and lines under current study.

In addition, apart from Czech and local $P$. vulgaris varieties and lines six French commercial accessions of bush and runner common beans have indicated high or average productivity in our conditions. Since cv. "Argus" is specific by its hybridization ability, it is obvious that the studies on bean domestication, crossing and molecular biology are essential. Further development of domestic bean collection along with the application of another eight directions of biology and biotechnology of legumes requires efforts both from researchers and authorities involved.

\section{Acknowledgement}

We thank our university for supporting our research.

\section{Author's Contributions}

All authors contributed equally.

\section{Ethics}

We declared no conflicts of interests.

\section{References}

Adams, R., 1974. Determination of amino acid profiles in biological samples by gas chromatography. J. Chromatography, 2: 188-212.

Asfaw, A., M.W. Blair and C. Almekinders, 2009. Genetic diversity and population structure of common bean (Phaseolus vulgaris L.) landraces from the East African highlands. Theor. Applied Genet., 1: 1-12.

Ballhorn, D.J., M. Schädler, J.D. Elias, J.A. Millar and S. Kautz, 2016. Friend or foe-light availability determines the relationship between mycorrhizal fungi, rhizobia and lima bean (Phaseolus lunatus L.). PLoS ONE, 2: 1-12. DOI: 10.1371/JOURNAL.PONE.0154116

Beattie, A.D., T.E. Michaels and K.P. Pauls, 2003. Predicting progeny performance in common bean (Phaseolus vulgaris L.) using molecular markerbased cluster analysis. Genome, 2: 259-267.

Berrocal-Ibarra, S., J. Ortiz-Cereceres and C.B. PecaValdivia, 2002. Yield components, harvest index and leaf area efficiency of a sample of a wild population and a domesticated variant of the common bean Phaseolus vulgaris. South Afr. J. Botany, 68: 205-211. DOI: 10.1016/S0254-6299\%2815\%2930421-X

Bisgaard, S., 2008. Must a process be in statistical control before conducting designed experiments? Quality Eng., ASQ, 2: 143-176.

Bodnar, G.V. and G.T. Lavrinenko, 1977. Grain Legume Crops. 1st Edn., USSR: Kolos, Moscow, pp: 256.

Büyük, İ., B. Inal, E. Ilhan, M. Tanriseven and S. Aras et al., 2016. Genome-wide identification of salinity responsive HSP70s in common bean. Mol. Biol. Rep., 43: 1251-1266. DOI: 10.1007/s11033-016-4057-0

Cullis, C. and K.J. Kunert, 2016. Unlocking the potential of orphan legumes. J. Experimental Botany, 68: 1-9.

Daryanto, S., L. Wang and P.A. Jacinthe, 2015. Global synthesis of drought effects on food legume production. PLoS ONE, 10: 1-16. DOI: 10.1371/journal.pone.0127401

Dospekhov, B.A., 1985. Field Experiment Techniques (with Fundamentals of Statistic Treatment of Research Data). 1st Edn., Agropromizdat, USSR, Moscow, pp: 351.

Fetahu, S., S. Aliu, I. Rusinovci, B. Kelmendi and N. Maliqi, 2013. Accumulation and distribution of dry matter in some common bean landrace seedlings at the phase of the cotyledons. Agric. Forestry, 59: 133-142.

Gómez, O., K. Wrobel, A.R.C. Escobosa, J.C.T. Elguera and E.G.S. Ma, 2015. Molybdenum and copper in four varieties of common bean (Phaseolus vulgaris): New data of potential utility in designing healthy diet for diabetic patients. Biol. Trace Elem. Res., 163: 244-254. 
Herrera, M.L., J.R.A. Rivera, C. Trejo and C.B. PenaValdivia, 2001. Differences in seed germination of wild and domesticated common bean (Phaseolus vulgaris L.) in response to storage. South Afr. J. Botany, 67: 620-628.

Hiz, M.C., B. Canher, H. Niron and M. Turet, 2014. Transcriptome analysis of salt tolerant common bean (Phaseolus vulgaris L.) under saline conditions. PLoS ONE, 9: 1-13.

Hyman, G., E. Barona, C. Biradar, E. Guevara and J. Dixon et al., 2016. Priority regions for research on dryland cereals and legumes. Food Res.

Isemura, T., A. Kaga, S. Konishi, T. Ando and N. Tomooka et al., 2007. Genome dissection of traits related to domestication in azuki bean (Vigna angularis) and comparison with other warm-season legumes. Ann. Bot. 100: 1053-1071.

Kavas, M., M.C. Baloglu, E.S. Atabay, U.T. Ziplar and H.Y. Dasëgan et al., 2016. Genome-wide characterization and expression analysis of common bean bHLH transcription factors in response to excess salt concentration. Mol. Genet. Genomics, 291: 129-143.

Korsakov, N.I., 1975. Methodical Instructions on The Study of The Collection for Grain Legume Crops. 1st Edn., All-Union Institute of Plant Research, Leningrad, USSR, pp: 59.

Kumar, V., S. Sharma, A.K. Sharma, M. Kumar and S. Sharma et al., 2008. Genetic diversity in Indian common bean (Phaseolus vulgaris L.) using random amplified polymorphic DNA markers. Physiol. Mol. Biol. Plants, 14: 383-387.

Kwak, M., O. Toro, D.G. Debouck and P. Gepts, 2012. Multiple origins of the determinate growth habit in domesticated common bean (Phaseolus vulgaris). Annals Botany, 110: 1573-1580.

Lamas, N.S., R.S. Fontenele, F.L. Melo, A.F. Costa, A. Varsani et al., 2016. Complete genome sequence of a genomovirus associated with common bean plant leaves in Brazil. Genome Announcements, 4: 1-1.

Marcenaro, D. and J.P.T. Valkonen, 2016. Seedborne pathogenic fungi in common bean (Phaseolus vulgaris cv. INTA Rojo) in Nicaragua. PLoS ONE, 11: 1-18.

Nanni, L., E. Bitocchi, E. Bellucci, M. Rossi and D. Rau et al., 2011. Nucleotide diversity of a genomic sequence similar to SHATTERPROOF $(P v S H P 1)$ in domesticated and wild common bean (Phaseolus vulgaris L.). Theorey Applid Genet., 123: 1341-1357.

Nowosielski, J., W. Podyma and D. Nowosielska, 2002. Molecular research on the genetic diversity of polish varieties and landraces of Phaseolus coccineus L. and Phaseolus vulgaris L. using the RAPD and AFLP methods. Cell Mol. Biol. Lett., 7:753-762.
Peña-Valdivia, C.B., A.B. Sánchez-Urdaneta, J.M. Rangel, J.J. Muñoz et al., 2010. Anatomical root variations in response to water deficit: Wild and domesticated common bean (Phaseolus vulgaris L.). Biol. Res., 43: 417-427.

Popov, V.P. and O.L. Martynov, 2001. Morphological and biological peculiarities of few cultivars for common bean in the South of Moscow Region. Proc. Russian Acad. Agric. Sci., 4: 21-23.

Ratushnyak, A.Y., A.A. Ratushnyak, M.G. Andreeva, A.R. Kayumov and M.I. Bogachev et al., 2012. Effect of lead and salicylic acid on some plant growth parameters in Pisum sativum L. World Applied Sci. J., 19: 1157-1159.

Rivera, N.G.R., C. Garcia-Salinas, F.J.L. Aragao and R.I. Diaz de la Garza, 2016. Metabolic engineering of folate and its precursors in mexican common bean (Phaseolus vulgaris L.). Plant Biotechno. J., 14: 2021-2032.

Sampath, H., V. Vartanian, M.R. Rollins, K. Sakumi and Y. Nakabeppu et al., 2012. 8-Oxoguanine DNA Glycosylase (OGG1) deficiency increases susceptibility to obesity and metabolic dysfunction. PLoS ONE, 7: 1-10.

Shekari, F., A.. Javanmard and M. Hassanpouraghdam, 2014. Response of two red bean (Phaseolus vulgaris L.) cultivars to controlled water deficit stress during post-flowering growth stage. Agric. Forestry, 60: 245-257.

Vasconcelos, E.V., A.F.A. Fonsêca, A. Pedrosa-Harand, K.C.A. Bortoleti and A.M. Benko-Iseppon et al., 2015. Intra-and interchromosomal rearrangements between cowpea [Vigna unguiculata (L.) Walp.] and common bean (Phaseolus vulgaris L.) revealed by BAC-FISH. Chromosome Res., 23: 253-266.

Wang, H.F., X.X. Zong, J.P. Guan, T. Yang and X.L. Sun et al., 2012. Genetic diversity and relationship of global faba bean (Vicia faba L.) germplasm revealed by ISSR markers. Theor. Applied Genet., 124: 789-797.

Zerfus, V.M., A.G. Schitov and G.Y. Kozlova, 1997. Factors determining the formation of symbiotic apparatus and its impact on grain legumes productivity in Western Siberia. Agrochemistry, 12: 27-31.

Zhang, S., J. Wei and L. Kang, 2012. Transcriptional analysis of arabidopsis thaliana response to lima bean volatiles. PLoS ONE, 7: e35867- e35867.

Zhang, X., M.W. Blair and S. Wang, 2008. Genetic diversity of Chinese common bean (Phaseolus vulgaris L.) landraces assessed with simple sequence repeat markers.Theor. Applied Genet. v., 117: 629-640.

Zhukovsky, P.N., 1971. Crops and their Relations. Kolos, Leningrad, USSR, pp: 791. 